\title{
Correction to: A cobalt oxide@polydopamine-reduced graphene oxide-based 3D photothermal evaporator for highly efficient solar steam generation
}

\author{
Ting Gao ${ }^{1} \cdot$ Xuan $\mathrm{Wu}^{1} \cdot$ Gary Owens ${ }^{1} \cdot$ Hao-Lan $\mathrm{Xu}^{1}$
}

Published online: 30 November 2020

(c) The Nonferrous Metals Society of China 2020

\section{Correction to: Tungsten \\ https://doi.org/10.1007/s42864-020-00062-6}

Due to an unfortunate oversight the mistake of the legend in Fig. 6a has been included. Please find below the correct Fig. 6. The original article has been corrected.
Publisher's Note Springer Nature remains neutral with regard to jurisdictional claims in published maps and institutional affiliations.
Fig. 6 a Concentrations of the major irons in the original seawater and condensed water collected during solar steam generation. b Stability test for the $3 \mathrm{D}$ evaporator with a height of $4.0 \mathrm{~cm}$ under 1.0 sun irradiation for eight cycles
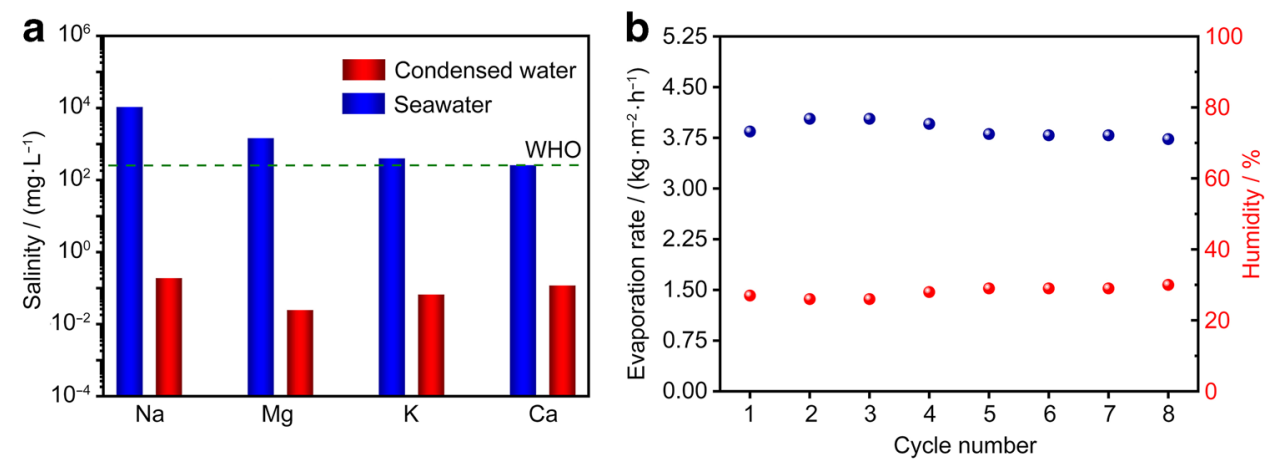

The original article can be found online at https://doi.org/10.1007/ s42864-020-00062-6.

Hao-Lan Xu

haolan.xu@unisa.edu.au

1 Future Industries Institute, University of South Australia, Adelaide, SA 5095, Australia 